\title{
Application Research of Hydraulic and Pneumatic Transmission Teaching based on TRIZ Theory and FESTO Simulation Software
}

\author{
Zhongbin Wei ${ }^{1, a^{*}}$, Song Zhao ${ }^{2, b}$ and Huijuan Zhao ${ }^{3, c}$ \\ Mechanical and electrical technology department, Xijing University, Xi'an, China

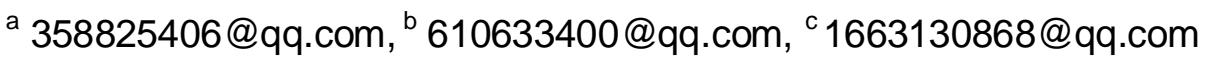

Keywords: TRIZ theory; FESTO simulation software; Innovative teaching; Teaching mode

\begin{abstract}
For in higher vocational teaching of hydraulic and pneumatic transmission problems, this article introduced the TRIZ theory and FESTO simulation software to apply to the daily teaching, the aim of the integration of teaching theory, practice and innovation, focus on cultivating students' innovation spirit and innovation ability. Through the application in class, homework and so on, based on TRIZ theory is constructed and the FESTO simulation software of teaching mode, achieved good teaching effect.
\end{abstract}

\section{Introduction}

Hydraulic and pneumatic transmission is one of the three transmission way with coexistence of mechanical drive and electrical drive, and it's one of the fastest developing speed in technology of mechanical equipment today. Hydraulic and pneumatic transmission course is a professional required course of higher vocational education, its theory and practice is very strong, the teaching quality and learning effect will directly influence the cultivation about students' professional ability and professional quality.

The teaching of the course in hydraulic and pneumatic transmission, the main problems are the following: 1, the students are not interested in, not enough emphasis; 2 , the theoretical of course is strong, which is difficulty to understand by students; 3, the appraisal way single, the homework is boring, etc.

We should adhere to "the employment oriented and develop practical skills talent" of the talent training scheme, so how to effectively solve the above problem, that is to cultivate the students' learning interest and improve students' study effect, make the students' professional ability and professional quality improved, is an urgent to explore the problem.

This paper studies the theory of TRIZ and the FESTO simulation software, which are applied in the hydraulic and pneumatic transmission daily teaching. The innovation theory and methods are introduced to the teaching in the classroom and homework, which have achieved good teaching effect.

\section{Build in teaching Mode Based on TRIZ Theory and FESTO Simulation Software}

\section{TRIZ theory}

TRIZ theory is a theory of invention problem, mainly includes the technology system evolution laws of its theoretical system, 40 innovation principle, technical contradiction matrix, separation methods of physical contradiction, etc. TRIZ theory has been widely used in machinery, electronics, management, education teaching and other fields, and good results have been achieved. Introducing the TRIZ theory in the hydraulic and pneumatic transmission teaching, could help to improve the ability of students to find and solve problems and innovation ability[1].

\section{FESTO Simulation Software}

FluidSIM is a software, which developed jointly by FESTO and the university of Paderborn, specifically for hydraulic, pneumatic and electric hydraulic, electric pneumatic circuit design and simulation. It includes FluidSIM-H which is used in the design of the hydraulic system and FluidSIM-P which is used in the design of pneumatic system. The software has a built-in rich component library and gas-liquid electrical integration of simulation function, and software is 
equipped with abundant teaching resources, including pictures, sectional view, the teaching practice and animation films, can be intuitive multimedia teaching[2]. The main characteristic of the software are: (1) can be closely linked to the functions of CAD and simulation together; (2) the study of system concept; (3)could design electrical control circuit which is match to hydraulic pneumatic circuit. The software has one of the most important function which is used in hydraulic and pneumatic circuit design and simulation. When the working is in edit mode and the software simulation model, or saving the loop, there will be appear error information about electric, mapping errors; The function of the CAD in software is special designed for fluid, such as in the drawing process, the software will check the connection between the components is feasible. If the circuit design correct that the simulation can be performed, and the element of state graph has displayed.

\section{The Construction of Teaching Mode}

The teaching of hydraulic and pneumatic transmission mainly consists two teaching links about theory teaching and practice teaching. The practice teaching has four parts which can be divided into classroom teaching, homework after class, experiment teaching and course design[3]. The classroom teaching mainly imparts theoretical knowledge, pay attention to students' mastery level of basic knowledge; The homework is to review and preview of classroom teaching and to consolidate the theoretical knowledge as the main goal; Experiment teaching is often appears in auxiliary method in the teaching of theory. For the most students, in order to deepen the understanding of theoretical knowledge; Course design is main to cultivate students' ability of knowledge integrate use. The traditional teaching model focused more on each teaching link, the cultivation of the students' learning ability and hands-on ability, so often ignore the cultivation of students' innovative ability[4]. The innovation ability is a kind of ability that talents must master in the new century; The cultivation of creative talents must be run through the whole course of higher education.

In the cultivation of innovation ability of the teaching, add the innovation teaching in the teaching link is an important part of cultivating innovative talents in colleges and universities. Innovation teaching is given priority to with innovation ability training, focusing on cultivating students' innovation consciousness, innovation qualities of the research-type learning.

Innovation teaching is the deepening and improving of the theory teaching and practice teaching, to cultivate students' innovation spirit, improve the innovative ability of students[5]. Based on theory teaching, practice teaching and innovative teaching mode of teaching, mutual supporting the university personnel training system, throughout the course of education teaching in colleges and universities.

Task driven teaching essence is induced by "task", strengthen and sustain learners' achievement motivation. Achievement motivation is the real driving force to complete the task and learning system. In the process of practice and learning, the students could be successful after a lot of practice, and could obtain the joy of needs, gradually strengthened the early intellectual curiosity, thus forming a relatively stable learning motivation. When designing task driven teaching mode, teachers as a designer, need to pay attention to the following a few questions[6].

(1) The design of the task should fit engineering application practice, as a guide to project. To make the design of the task adjoin to students learning and life experience. For a production enterprise actual project, the teaching content should have corresponding background knowledge foreshadowing. For example, the machining center hydraulic loop task, students need to has a preliminary understanding to appearance, structure, working principle of machining center. Otherwise, not easy to understand and analysis the system requires the clamping cylinder, such as feed cylinder actuators.

(2) In the process of task implementation, the teacher should guide the student to realize the task, the outline of the target and the significance. Try to create conditions for teachers, guide students to complete the task. But not too much interference, students won't be able to truly experience the joy of success. The teacher should protect students' curiosity, to improve students find problems and the courage to ask questions, encourage students to explore independently and to complete the task. For example, Hydraulic cylinder differential connection task, has been under the teachers teach students 
to understand the actuators using common connection is needed in circuit implementation speed movement, using the differential connection to realize the quick and the next step need to choose components implement both on at some point in the stroke switch. This requires the students in the first order of acquisition in the course of reversing valve and stroke control knowledge, and its logical reasoning. At this point, the teacher should sink, stimulates the student to design, in the hope of happy, confident and satisfied after the success.

(3) In the process of task examination and evaluation, teachers should guide and summary in time, make the student know clearer and profound to the acquisition of skills, experience, and literacy cultivation. The teacher wants to compliments, and achievements and show it to the student's personality shines give affirmation and encouragement.

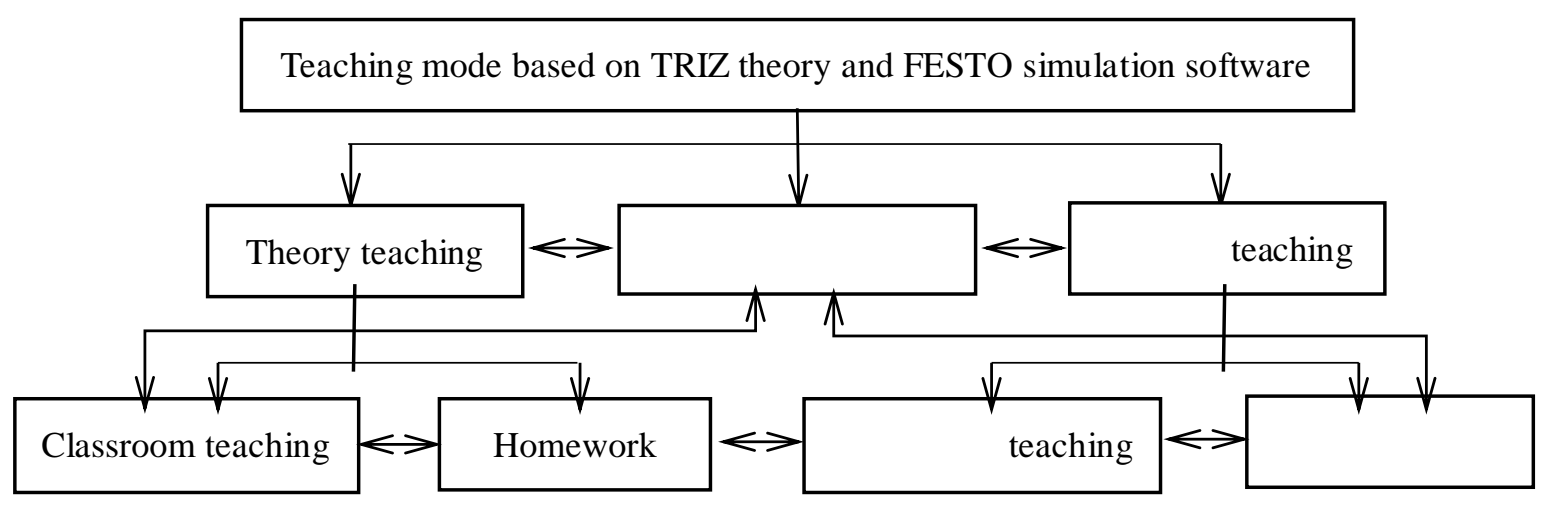

Figure1. Course teaching model

\section{Application Research}

\section{The Application of TRIZ Theory and FESTO Simulation Software in Classroom Teaching}

The TRIZ theory and FESTO simulation software are introduced to classroom teaching, which could coalesce every link of classroom teaching, to improve the classroom teaching environment, active classroom atmosphere, improve students' ability of thinking. Technology system evolution is one of the important theory of TRIZ theory, as products and biological system has the same development and evolution. The TRIZ theory summary deal with the completeness law, energy transfer law, dynamic evolution law, improve the degree of ideal law, subsystem uneven evolution law and so on[7].

FESTO simulation software in the curriculum practice, the application of hydraulic and pneumatic transmission, make students realize the (1) accept the task;(2) using the FESTO simulation software to complete the circuit design and simulation debugging;(3) using the training sets for actual circuit installation and fault test "the complete process, in the practice teaching environment, not only can cultivate the students' design and self-study ability, and can make students further understand the hydraulic and pneumatic equipment and the application of production line[8].

\section{Conclusion}

The TRIZ theory has been widely applied in various fields of higher education; Especially in the innovative talent training, curriculum reform in the universities, it has played a huge role in promoting. Based on the theory of TRIZ and FESTO simulation software, the innovation theory and methods of TRIZ theory are introduced into the teaching of each link in the hydraulic and pneumatic transmission, to explore the application of TRIZ theory in the teaching link, provide space for students to think, let the students really involved in the teaching process design, provide an effective way for the cultivation of innovative talents. Building course teaching model based on TRIZ theory and FESTO simulation software, which combined the theory teaching, practice teaching with innovative teaching, can be generalized to other courses reform, and produced a great 
guiding significance on the whole machinery of professional curriculum system reform.

\section{Acknowledgments}

The work in this article is supported by scientific research fund of Xijing university (No. XJ160117)

\section{References}

[1] Li Fuxing. Innovative talents training mode research Based on the theory of TRIZ [J].Journal of Higher Education, (2016)No.17, p33-35.

[2] Zhou Chuang, Zhao Fenglian. Exploration and Practice on the Teaching Reform of the Course of Hydraulic and Pneumatic Transmission [J].Modern Manufacturing Technology and Equipment, (2016)No.12,p187-188.

[3] Wang Congcong, Zhang Lemei. The teaching of "hydraulic and pneumatic transmission for the integration of teaching reform [J]. Modern Economic Information, (2016)No.15, p460.

[4] Wang Chao. Exploration and Practice of Theory-Practice Integration Teaching Reform of "Hydraulic and Pneumatic Transmission"in Higher Vocational Colleges [J]. JOURNAL OF BEIJING POLYTECHNIC COLLEGE, Vol.16 (2017) No.2, p73-76.

[5] Zhao Zhifang, Xu Ruiya. The innovative personnel educational mode research in higher vocational colleges based on the theory of TRIZ [J]. Science \& Technology Vision, (2017)No.02, p78.

[6] Song Feiyan. Based on the FESTO hydraulic pneumatic practice training platform of collaborative task practice teaching[J]. SCIENCE \& TECHNOLOGY INFORMATION, (2015)No.05, p170.

[7] Tong Guiying, Li Wenzhuo, Hou Zhigang. Construction of Practical Experiment Station of Hydraulic and Pneumatic Transmission [J]. MACHINE TOOL \& HYDRAULICS, Vol.41(2013)No.14, p70-71.

[8] Zhao Xiuhua, Wang Qiumin. Application of FESTO Experiment System in Practical Teaching of Hydraulic and Pneumatic Transmission Course [J]. MACHINE TOOL \& HYDRAULICS, Vol.38(2010)No.22, p86-88. 